\title{
EDITORIAL
}

\section{Los secretos que esconden los ritmos biológicos}

$\mathrm{E}$ n el campo de la endocrinología, el conocimiento de los ritmos biológicos es fundamental para entender la fisiopatología de algunas enfermedades y para el diagnóstico de otras. Vale la pena retomar algunos aspectos de esta temática, de una manera sucinta.

Se define como ritmo a todo patrón recurrente, dentro de un margen de tiempo. Probablemente los seres vivos han estado obligados a adaptarse a las consecuencias de los movimientos de la Tierra (rotación y traslación), lo que ha implicado una disponibilidad de nutrientes y un clima alternante y en ocasiones incierto: los seres vivos, a su vez, debieron asumir cambios adaptativos que pueden ser metabólicos, reproductivos o de crecimiento: esta amplia gama de adaptaciones temporales y cíclicas se denominan ritmos biológicos, esta ciclicidad biológica permitió a las especies sobrevivir. Debemos aclarar que los anteriores postulados son plausibles, desde un punto de vista biológico y conceptual; sin embargo, no se ha podido comprobar la causalidad de estos ritmos.

Los ritmos biológicos fueron por primera vez descritos hace más de 25 siglos. Andróstenes (siglo IV a. C.) observó que la posición de las hojas de algunas especies papilomaceas cambiaba de acuerdo con la hora del día y a la intensidad lumínica de la habitación donde se encontraba la planta; Aristóteles y Galeno discutieron sobre la periodicidad del sueño y el posible centro corporal que lo regulaba. En 1729 se presentó en la Real Academia de Ciencias de París el trabajo del astrónomo Jean Dòrtous De Marian, quien estudió los movimientos de la planta mimosa púdica, que abría las hojas durante el día y las cerraba en la noche, además demostró que al cambiar la planta a un sitio oscuro, su movimiento persistía, dando a entender que este comportamiento era endógeno y ya no requería el estímulo medioambiental. En el año 1832, Agustín de Candolle, demostró que esta planta además tenía un ritmo de cierre y apertura de aproximadamente 22 horas. Con base en estos elementos, Carlos Darwin escribió el libro, El poder del movimiento de las plantas.

En la actualidad se acepta que los ritmos biológicos son mecanismos adaptativos de los seres vivos a las condiciones exógenas, estos mecanismos se gestaron a través de millones de años y son regulados finamente por grupos de genes. Al hacer parte del genoma de la especie, con frecuencia, ya no requieren el estímulo del medio externo.

Por tanto, los ritmos biológicos en el verdadero sentido de la palabra son aquellas oscilaciones que continúan aún en ausencia de cambios periódicos en el ambiente, como cambios en la temperatura y la luz, etc ${ }^{(1,2)}$.

Los estudiosos de estos ritmos, también llamados cronobiólogos, describen cuatro grandes grupos de ritmos biológicos, los cuales están sincronizados con ciclos geofísicos a saber: los ciclos estacionales, los ciclos lunares, los ciclos mareales y, por último, el más interesante para los médicos, los ciclos circadianos, los cuales están sincronizados con el ciclo luz-oscuridad del día, suelen durar entre 22 y 24 horas, o sea casi un día, por eso se les denomina circadianos, que en latín significa cerca de un día (término introducido en 1959 por el doctor Franz Halberd, Universidad de Minnesota).

El ciclo circadiano consta básicamente de los siguientes componentes: vía de entrada para la sincronización, un oscilador autosostenido (reloj), encargado de establecer los periodos y las fases (el tiempo que una oscilación requiere para cumplir un ciclo completo), y un último componente, que es el conjunto de vías de salida.

Los ciclos circadianos pueden estar presentes a nivel de una sola célula (organismos unicelulares), en animales más complejos se presentan en forma de órganos: por ejemplo, el ganglio cerebral de la polilla, los ojos de la aplisiala, la glándula pineal en las aves y el núcleo supraquiasmático de los mamíferos.

En los mamíferos, el reloj (oscilador) del ciclo circadiano reside en el núcleo supraquiasmático (que a su vez se divide en dorsal y ventral) ubicado en el hipotálamo ventral, contiene cerca de 20.000 neuronas, que son las encargadas de generar los ciclos circadianos. El sistema nervioso central se encarga de sincronizar estos ciclos, extrayendo información del ciclo día-noche, esta información llega al hipotálamo, por vía del tracto retino-hipotalámico (vía de entrada para la sincronización), una vez llega al núcleo supraquiasmático, se expresan y se liberan neuropéptidos (péptido liberador de gastrina, VIP y vasopresina). Se ha comprobado que este núcleo tiene pequeñas agrupaciones neuronales, encargadas de generar diversos ciclos circadianos, reguladas por asas de retroalimentación cortas. Estos neuropéptidos estimulan varios factores de trascripción, entre los que se destacan: el transcription factor Circadian Locomotor Output Cycles Kaput (CLOCK) y el Brain and Muscle ARNT-like protein 1 (Bmal1), que a su vez estimulan la expresión de genes específicos: per1, per2, per3, Cry1, Cry2: por último esto se va a traducir en una actividad eléctrica, la cual cambiará de acuerdo con el momento del ciclo (día-noche). 
Lo más interesante es que si se aislan las neuronas que hacen parte de este núcleo no pierden la capacidad de oscilar autónomamente, lo cual nos puede indicar que las neuronas trabajan en equipo, para constituirse en verdaderos marcapasos ${ }^{(2,3)}$.

Por último, no debemos olvidar otro actor importante para muchos vertebrados: la melatonina, que fue descubierta por Lerner y colaboradores, en 1958, estos investigadores aislaron en pineales de bovinos, el factor causante del blanqueamiento de la piel de los anfibios: hoy se sabe que la melatonina es una señal potente para los ritmos circadianos y estacionales de varias especies.

La melatonina tiene un pico máximo de secreción en la oscuridad o en estaciones de baja intensidad lumínica. En la mayoría de las especies, el ritmo circadiano de la melatonina pineal está regulado por señales polisinápticas originadas en el núcleo supraquiasmático que, como se mencionó previamente, es donde se aloja el reloj del ciclo circadiano.

Las funciones de la melatonina no están definidas en los humanos; sin embargo, en otras especies se han descrito algunas: inhibe la GNRH durante el periodo prepuberal y prerreproductivo, estimula la síntesis de prolactina en la primavera y el verano, estimula la TSH, aumenta la sensibilidad a la insulina y tiene efecto antihiperglicémico.

Dado que los receptores de melatonina se encuentran en casi todas las células del organismo, se ha postulado como un candidato atractivo, encargado de sincronizar todos los órganos del cuerpo al reloj biológico; podría ser la vía principal de salida del reloj biológico de los mamíferos hacia las células somáticas ${ }^{(4)}$.

En el presente número, el doctor Arturo Orrego, publica el artículo: Exposición a la luz nocturna, Disrupción del ritmo circadiano y la obesidad.

La hipótesis expuesta por el autor, desde el punto de vista biológico es muy tentadora y los descubrimientos de la última década pueden apoyarla.

Lo planteado por el doctor Orrego coincide con los rudimentos actuales de conocimiento alrededor de los ritmos biológicos y se está constituyendo en un nicho importante para investigación de los trastornos metabólicos ligados con la obesidad y la diabetes.

Por último, no sobra "predecir" que, en la medida en que la ciencia entienda mejor estos fenómenos adaptativos, seguramente tendremos elementos invaluables para terapéutica e incluso para la supervivencia de los seres vivos. Los ritmos biológicos y los diversos mecanismos que los regulan encierran muchos secretos: cómo es el control del sueño y la vigilia, las fases metabólicas del organismo, el control de la pubertad desde sus inicios, los cambios afectivos relacionados con el clima y los ciclos luz-oscuridad.

\section{Roberto Franco Vega}

Médico Endocrinólogo

Profesor titular de la Facultad de Medicina, Universidad Nacional de Colombia

Miembro de Número de la Asociación Colombiana de Endocrinología, Diabetes y Metabolismo

Miembro del Comité Editorial de la Revista Colombiana de Endocrinología, Diabetes y Metabolismo

\section{Referencias}

1. Jonathan D Johnston and Debra J. Skene. Regulation of mammalian neuroendocrine physiology and rhythms by melatonin. Journal of Endocrinology (2015); 226:T187-T198.

2. Ashna Ramkisoensing and Johanna H. Meijer. Synchronization of biological clock neurons by light and peripheral feedback systems promotes circadian rhythms and health. Front. Neurol.2015; 6:128. doi: 10.3389/fneur.

3. Johnston JD 2005 Measuring seasonal time within the circadian system: regulation of the suprachiasmatic nuclei by photoperiod Journal of Neuroendocrinology $2005 ; 17: 459-465$.

4. McMullan CJ, Curhan GC, Schernhammer ES \& Forman JP. Association of nocturnal melatonin secretion with insulin resistance in nondiabetic young women. American Journal of Epidemiology 2013;178: 231-238. 